Article

\title{
Progress on Low-Temperature Pulsed Electron Deposition of CuInGaSe 2 Solar Cells
}

\author{
Massimo Mazzer ${ }^{1}$ * , Stefano Rampino ${ }^{1}$, Enos Gombia ${ }^{1}$, Matteo Bronzoni ${ }^{1}$, Francesco Bissoli ${ }^{1}$, \\ Francesco Pattini ${ }^{1}$, Marco Calicchio ${ }^{1}$, Aldo Kingma ${ }^{1}$, Filippo Annoni 1,2, Davide Calestani ${ }^{1}$, \\ Nicholas Cavallari ${ }^{1,2}$, Vimalkumar Thottapurath Vijayan ${ }^{1,3}$, Mauro Lomascolo ${ }^{4}$, Arianna Cretì 4 \\ and Edmondo Gilioli ${ }^{1}$ \\ 1 Consiglio Nazionale delle Ricerche-Istituto Materiali per l'Elettronica e il Magnetismo (CNR-IMEM), \\ Parco Area delle Scienze 37/a, Parma 43124, Italy; stefano.rampino@cnr.it (S.R.); gombia@imem.cnr.it (E.G.); \\ matteo.bronzoni@imem.cnr.it (M.B.); francesco.bissoli@cnr.it (F.B.); francesco.pattini@cnr.it (F.P.); \\ calicchio@imem.cnr.it (M.C.); aldo.kingma@imem.cnr.it (A.K.); filippo.annoni@studenti.unipr.it (F.A.); \\ davide.calestani@cnr.it (D.C.); nicholas.cavallari@imem.cnr.it (N.C.); vimalthottapurath@gmail.com (V.T.V.); \\ edmondo.gilioli@cnr.it (E.G.) \\ 2 Department of Physics, University of Parma, Parma 43124, Italy \\ 3 Department of Physics, St.Thomas' College, Thrissur, Kerala 680001, India \\ 4 Consiglio Nazionale delle Ricerche-Istituto di Microelettronica e Microsistemi (CNR-IMM), \\ University Campus, Lecce 73100, Italy; mauro.lomascolo@cnr.it (M.L.); arianna.creti@le.imm.cnr.it (A.C.) \\ * Correspondence: massimo.mazzer@cnr.it; Tel.: +39-0521-260-208
}

Academic Editor: José Antonio Sánchez Pérez

Received: 15 January 2016; Accepted: 11 March 2016; Published: 16 March 2016

\begin{abstract}
The quest for single-stage deposition of CuInGaSe 2 (CIGS) is an open race to replace very effective but capital intensive thin film solar cell manufacturing processes like multiple-stage coevaporation or sputtering combined with high pressure selenisation treatments. In this paper the most recent achievements of Low Temperature Pulsed Electron Deposition (LTPED), a novel single stage deposition process by which CIGS can be deposited at $250^{\circ} \mathrm{C}$, are presented and discussed. We show that selenium loss during the film deposition is not a problem with LTPED as good crystalline films are formed very close to the melting temperature of selenium. The mechanism of formation of good ohmic contacts between CIGS and Mo in the absence of any $\mathrm{MoSe}_{2}$ transition layers is also illustrated, followed by a brief summary of the measured characteristics of test solar cells grown by LTPED. The 17\% efficiency target achieved by lab-scale CIGS devices without bandgap modulation, antireflection coating or K-doping is considered to be a crucial milestone along the path to the industrial scale-up of LTPED. The paper ends with a brief review of the open scientific and technological issues related to the scale-up and the possible future applications of the new technology.
\end{abstract}

Keywords: photovoltaics; thin films; pulsed electron deposition; CuInGaSe 2 (CIGS)

\section{Introduction}

Thin film photovoltaic technologies have made dramatic progress over the last seven years, both in terms of solar cell efficiency and production cost. CuInGaSe 2 (CIGS) solar cells have recently passed the $22 \%$ efficiency mark at the laboratory scale while the average spot price of commercial CIGS modules oscillates around $€ 0.55 / \mathrm{Wp}$.

At a price of $€ 0.5 / \mathrm{Wp}$ self-generated PV electricity is already significantly cheaper than grid electricity for residential consumers in several countries including Germany, Italy, Spain and Australia, even in the absence of any incentive [1]. In fact, autoconsumption of PV energy in buildings is bound to evolve very rapidly from being a niche market to become a key segment of the PV market. The reason is that domestic, commercial and public buildings together, account for more than $40 \%$ 
of the primary energy consumption in both the EU and the USA and use about $72 \%$ and $58 \%$ of the electricity distributed by the grid in the USA and the EU, respectively.

For these reasons the photovoltaic industry has already started to differentiate their portfolio of products and a variety of new photovoltaic modules specifically designed for building integrated (BIPV) applications have been developed by taking advantage of lightness and flexibility of thin film solar cells.

Thanks to its high efficiency and to the rapid progress made by leading research groups and manufacturers like Solar Frontier, CIGS is now the fastest expanding thin film technology in spite of the large investments required for standard production lines using multiple-stage CIGS deposition technologies based on sputtering [2] or coevaporation [3].

Low-Temperature Pulsed Electron Deposition (LTPED) is a novel single-stage growth technology by which photovoltaic-grade CIGS can be deposited on a variety of different substrates including ultra-lightweight metal foils and polyimide, with no need for post-deposition treatments like selenisation or high temperature annealing.

Besides being attractive for the positive impact a single-stage deposition technology may have on the manufacturing costs of CIGS solar cells, the key feature of LTPED which makes it very attractive for industrial applications is the very low substrate temperature needed for the growth of good quality polycrystalline [4] and epitaxial [5] CIGS, that is $250-300{ }^{\circ} \mathrm{C}$ instead of the $450-600{ }^{\circ} \mathrm{C}$ required by sputtering [6] or coevaporation [7]. In fact it is the combination of low substrate temperatures and the unique properties of the PED ablation process that make it possible to obtain high efficiency solar cells by single stage CIGS deposition.

This paper briefly summarises the main characteristics of LTPED and provides evidence of the material and device quality obtained by optimising the CIGS growth conditions. Sodium doping and other important process steps used by industrial-grade technologies to reach solar cell efficiencies of the order of $20 \%$ have been successfully adapted to LTPED to achieve similar results. How these steps were implemented and the path towards a full integration of LTPED in a typical cell manufacturing process will also be discussed.

The solar cells presented in this paper, referred to as "basic solar cells", are based on ungraded (single bandgap) CIGS doped with sodium only. The study of the compatibility of process steps currently used to enhance the efficiency of CIGS solar cells like potassium doping [8], CIGS band-gap grading [9] or back-contact passivation [10], with LTPED is beyond the subject of this work and will be presented in a forthcoming publication.

\section{Results}

The basic characteristics of the LTPED process were described in a previous paper [11] where the fabrication of CIGS solar cells exceeding 15\% efficiency was reported for the first time. The key specifications of the deposition process used in this work are described in Section 4.

The core of the LTPED process is the interaction between a high power pulsed electron beam and a few millimeter thick CIGS target having the stoichiometry to be reproduced in the thin film. Each pulse lasts about $200 \mathrm{~ns}$ during which an average power of $10^{8} \mathrm{~W} / \mathrm{cm}^{2}$ is dissipated in a volume of a few $\mathrm{mm}$ in diameter and $1 \mu \mathrm{m}$ in depth. As a result a significant portion of the bombarded material is ablated and gives rise to a plasma containing all the elements of the compound in essentially the same proportion as in the original target. The interaction between the plasma and the substrate gives rise to the film deposition.

Two main key side effects need to be controlled in order to minimise their impact on the quality of the deposited film. Both side effects are caused by heat dissipation in the bombarded volume where part of the non-ablated material may partially melt or be fractured and generate debris up to tens of microns in size. As a result the plasma contains two unwanted material contributions. One is the effect of the evaporation from the thin layer of melt formed at the surface of the target [12] and the second is a flow of debris which may reach the substrate even if it is oriented face-down to take advantage of the 
gravitational force [13]. Both contributions depend primarily on the energy of the electron beam and need to be minimised to avoid negative effects on the solar cell performance.

\subsection{CIGS Film Morphology and Stoichiometry}

Figure 1 illustrates the effect of changing the electron beam accelerating voltage on the film morphology and both the ablation and the evaporation rates. As discussed in detail in a previous publication [12], the angular distribution of ablated and evaporated material is substantially different, the ablation cone being much narrower than the evaporation cone. Moreover the composition of the evaporated film is determined by the local thermodynamic equilibrium conditions which favour the formation of the ordered defect compound (ODC) phase $\mathrm{Cu}(\mathrm{InGa})_{3} \mathrm{Se}_{5}$ having about half the $\mathrm{Cu}$ content with respect to photovoltaic-quality phase. This means that the two contributions to the total thickness of a deposited film for a specific beam energy can be estimated by mapping the film composition and thickness. This is how the histogram in Figure 1 was obtained to reveal the existence of an energy threshold at $12 \mathrm{kV}$ for the onset of the ablation process. Above that threshold the ablated fraction increases almost linearly as a function of the beam energy at a rate of about $10 \mu \mathrm{g} / \mathrm{pulse} / \mathrm{kV}$ while the evaporated fraction does not change appreciably on the same scale and becomes negligible above $14 \mathrm{kV}$. On the other hand the morphological quality of the films degrades with increasing beam energy as both the density of particulate and the size of the largest particles increase. It is important to bear in mind that the best compromise between high deposition rate and good morphological quality also depends on the specifications of the electron gun and the deposition chamber. In particular the shape of the energy pulse (power vs. time), the pressure inside the growth chamber, the morphology and the density of the CIGS target and the relative position of electron source, target and substrate contribute to move the balance between the two competing effects and therefore to change the window of optimum beam energy values.

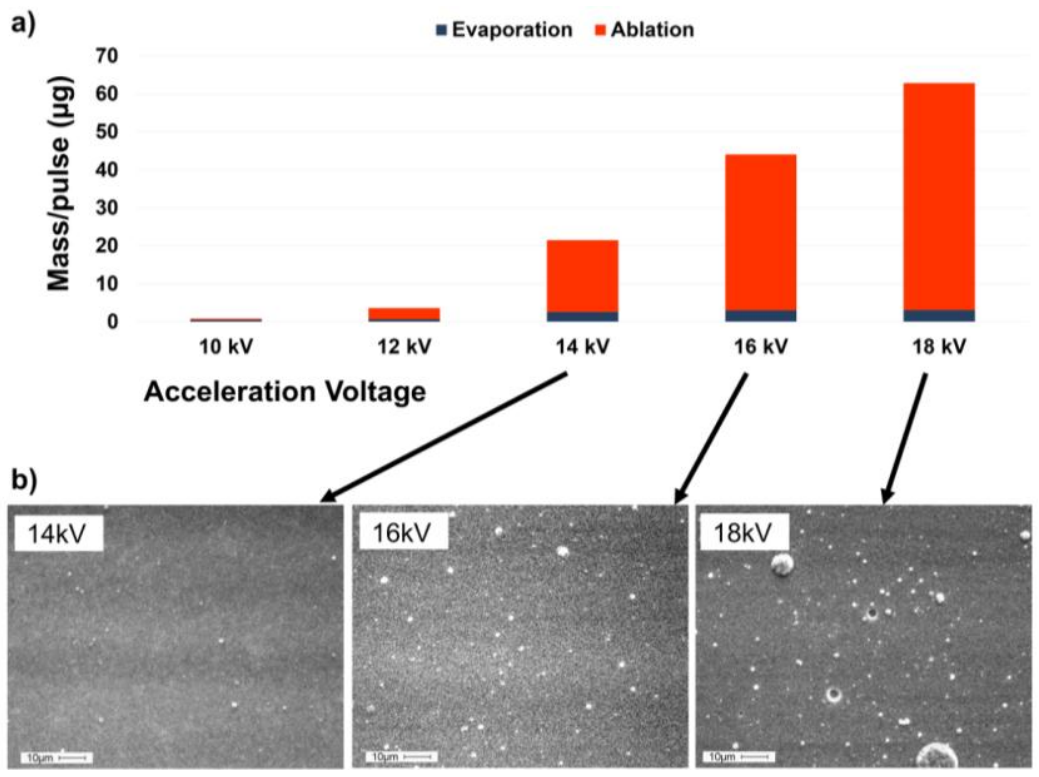

Figure 1. (a) Bar chart reporting the total deposition rate as a function of the electron beam energy. The blue and the orange sections of the bars represent the evaporated and the ablated fraction of the target material; (b) Scanning Electron Microscope images of the CIGS surface obtained with the electron source operating at $14 \mathrm{kV}, 16 \mathrm{kV}$ and $18 \mathrm{kV}$.

The results reported in this paper were obtained with a PEBS-20 commercial source (Neocera Inc., Beltsville, MD, USA) operating under a vacuum of $5.0 \times 10^{-3} \mathrm{mbar}-\mathrm{Ar}$ with a distance between target and substrate of about $8 \mathrm{~cm}$. The CIGS targets were obtained by a high temperature and 
moderate pressure synthesis process starting from elemental species $(\mathrm{Cu}, \mathrm{In}, \mathrm{Ga}$, and Se with $5 \mathrm{~N}$ purity). This process, previously developed for the synthesis of high-purity polycrystalline targets of CdTe [14], is specifically developed to widen the window of optimum beam energy values. Different electron beam sources and growth conditions are being explored to move the window towards large deposition rates as part of the effort to make the process compatible with industrial scale production of CIGS solar cells.

\subsection{Effects of Substrate Temperature}

A second dimension of the window of optimum growth parameters is defined by the substrate temperature. In this case the tradeoff is between the crystalline quality of the film, favoured by high temperatures, and the selenium incorporation which rapidly degrades with increasing temperature.

The energy of the plasma generated by the electron beam ablation of CIGS targets is of the order of $1-10 \mathrm{eV}$ [15] and may cause the formation of crystalline films even when the substrate is at room temperature. X-ray diffraction measurements show that just above room temperature the prevalent crystalline orientation of the deposited film is (220), then the density of (112) grains increases with increasing temperature until this orientation prevails over the (220) one. The crossover temperature appears to increase with the ratio between gallium and gallium+indium concentrations (GGI) being lower than $270{ }^{\circ} \mathrm{C}$ at GGI $=0.30$ [4] and about $450{ }^{\circ} \mathrm{C}$ at GGI $=1$ [15]. The size of the grains may vary from tens of $\mathrm{nm}$ at room temperature to $1-2 \mu \mathrm{m}$ above $400^{\circ} \mathrm{C}$. No appreciable difference in the solar cell efficiency seem to be correlated with either the relative density of (220) and (112) grains or the size of the grains.

Selenium re-evaporation is the most critical effect which makes single stage CIGS deposition so difficult to obtain with techniques requiring high deposition temperatures. The metallic selenium melting point is about $220^{\circ} \mathrm{C}$ and its vapour pressure is 4 mbar at $300{ }^{\circ} \mathrm{C}$ and reaches about $70 \mathrm{mbar}$ at $500{ }^{\circ} \mathrm{C}$. Thanks to the good crystalline quality obtained even below the selenium evaporation temperature, LTPED can minimise the problem of selenium depletion from the deposited film. In fact $15 \%$ to $17 \%$ efficient basic solar cells can be obtained with substrate temperatures between $250{ }^{\circ} \mathrm{C}$ and $270{ }^{\circ} \mathrm{C}$. At higher temperatures the effects of selenium depletion can be clearly seen in the I-V curves of basic solar cells as in the example shown in Figure 2.

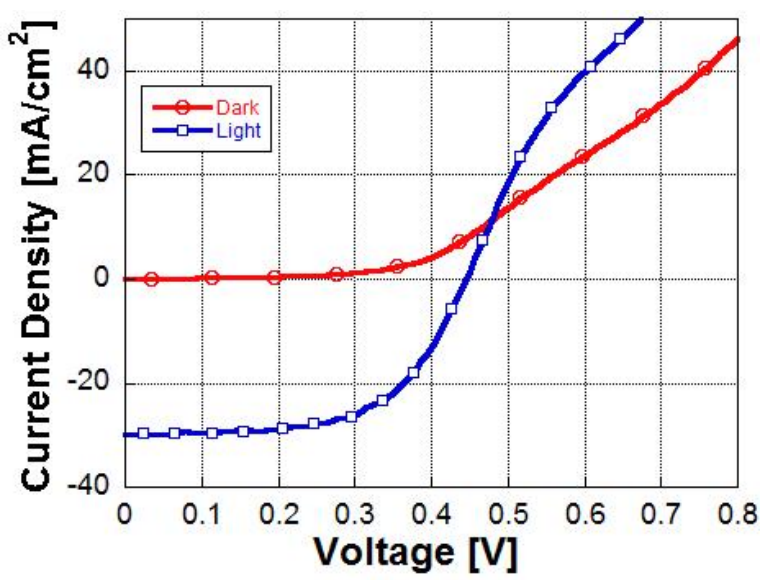

Figure 2. Dark (red circles) and illuminated (blue squares) characteristics of a CIGS solar cell where the absorber layer is deposited at $500{ }^{\circ} \mathrm{C}$. The corresponding cell parameters are: $\mathrm{Voc}=444 \mathrm{mV}, \mathrm{FF}=58.6 \%$, $\mathrm{Jsc}=30.1 \mathrm{~mA} / \mathrm{cm}^{2}, \eta=7.8 \%$.

Here the strong rollover effect in the light I-V curve is consistent with the presence of a high density of Se vacancies at the interface between the CIGS absorber and the buffer layer as reported in the literature [16].

Figure 3 shows the comparison of low-temperature photo-luminescence (PL) emission of devices grown by pulsed electron deposition at high $\left(D_{1}\right)$ and low temperature $\left(D_{2}\right)$. The broad and structured 
emission spectrum of sample $\mathrm{D}_{1}$, far from the band edge (Eg) of about $1.15 \mathrm{eV}$, clearly shows the presence of a large number of different defects states. In this sample the CIGS absorber layer, deposited at $500{ }^{\circ} \mathrm{C}$, clearly suffers from Se depletion as appears from the emission at about $80 \mathrm{meV}$ from the band edge [17] alongside with the broad emission band usually attributed to deep ( $250 \mathrm{meV}$ from Eg) donor defect related to In and $\mathrm{Cu}$ [17]. On the contrary in sample $\mathrm{D}_{2}$, grown by LTPED at $270{ }^{\circ} \mathrm{C}$ a single emission band is present. This is also a sign of the good interplay between low growth-temperature and sodium doping as discussed in the next paragraph.

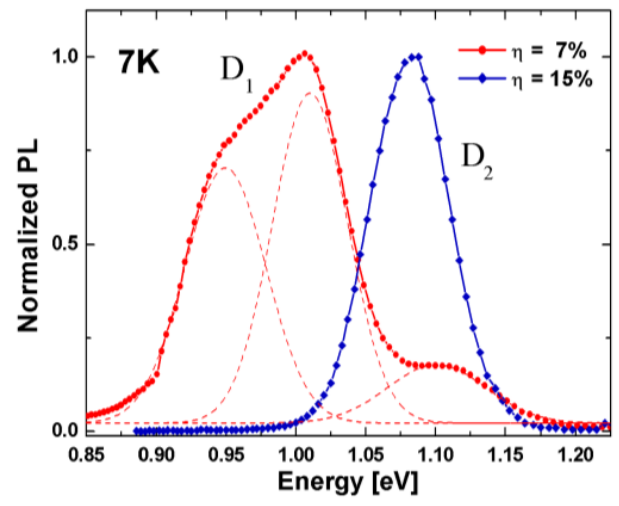

Figure 3. Low-temperature photoluminescence spectra of two PED-grown CIGS samples. Sample $\mathrm{D}_{1}$ was deposited at a substrate temperature of $500{ }^{\circ} \mathrm{C}$, sample $\mathrm{D}_{2}$ at $270{ }^{\circ} \mathrm{C}$ (LTPED).

\subsection{Sodium Incorporation and Its Effects}

It is widely accepted that sodium plays at least a twofold role in improving the efficiency of a CIGS-based solar cell [18]. On one hand it contributes to the partial compensation of electrically active defects mainly located at the grain boundaries but it is also expected to contribute to the quality of the ohmic contact between CIGS and molybdenum.

In the case of LTPED grown CIGS on Mo, no $\mathrm{MoSe}_{2}$ is detected by analytical TEM analysis at the interface as the substrate temperature is much lower than the $410{ }^{\circ} \mathrm{C}$ reported to be the onset for the formation of $\mathrm{MoSe}_{2}$ [19]. Nevertheless the introduction of a few nm thin buffer layer of sodium fluoride between Mo and CIGS ensures that a good ohmic contact is formed at low temperature in the absence of $\mathrm{MoSe}_{2}$.

In order to investigate the electrical behaviour of CIGS/Mo back-contact, Au/CIGS/Mo and $\mathrm{Au} / \mathrm{CIGS} / \mathrm{NaF} / \mathrm{Mo}$ structures on glass substrates were prepared [20]. The Au/CIGS contacts were used to ensure a sufficient ohmic characteristics of the top contact [21] and allow the detection of the the resistivity changes at the back contact. The I-V curves measured for both structures are reported in Figure 4. They clearly show the transition from rectifying to ohmic behaviour with and without the NaF layer respectively. These results explain why series resistances as low as $0.2 \Omega \cdot \mathrm{cm}^{2}$ can be achieved in solar cells grown at substrate temperatures as low as $250{ }^{\circ} \mathrm{C}$ in the presence of a NaF buffer layer on top of the Mo back-contact.

If the low substrate temperature is not a problem for the formation of the back ohmic contact, sodium diffusion into the CIGS film at $250{ }^{\circ} \mathrm{C}$ is much less effective compared to CIGS cells grown and annealed at temperatures as high as $600{ }^{\circ} \mathrm{C}$. Increasing the thickness of the $\mathrm{NaF}$ buffer layer to enhance Na diffusion is not an option as CIGS adhesion on Mo is compromised by a NaF thickness exceeding a critical value of about $30 \mathrm{~nm}$. In the case of the basic CIGS solar cells reported in this paper the CIGS film thickness was limited to $1.6 \mu \mathrm{m}$ to ensure an optimum sodium diffusion through the whole film. Alternative solutions to tune the Na diffusion profile and extend the diffusion range without exceeding the critical Na concentration in CIGS have been explored. The basic idea is to incorporate additional NaF nanolayers in the CIGS film during the growth. The work is still in progress and will be published soon. 

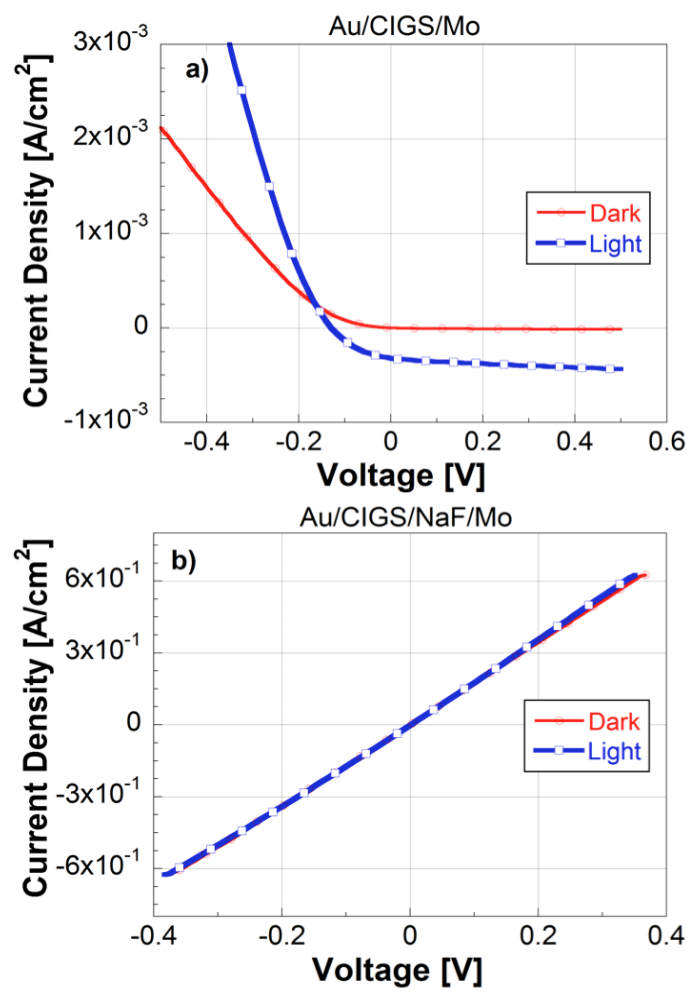

Figure 4. IV characteristics in the dark (red curves) and under illumination (blue curves) of the (a) Au/CIGS/Mo and (b) Au/CIGS/NaF/Mo structures deposited on a glass substrate. The curves clearly indicate the CIGS/Mo contacts to be rectifying and ohmic in the sample without and with $\mathrm{NaF}$, respectively.

\subsection{Electrical Properties of Devices}

The electrical properties of LTPED-grown CIGS solar cells are comparable to the state-of-the-art results published in the literature [2]. Figure 5 shows the $\mathrm{C}-\mathrm{V}$ plot at $120 \mathrm{~K}$ and $300 \mathrm{~K}$ of a solar cell representative of the standard cells based on LTPED-grown CIGS at $250{ }^{\circ} \mathrm{C}$. From the minimum of the typical u-shaped curve at $120 \mathrm{~K}$ [22] a rough estimation of the CIGS free carrier concentration is found to be of the order of $10^{15} \mathrm{~cm}^{-3}$.

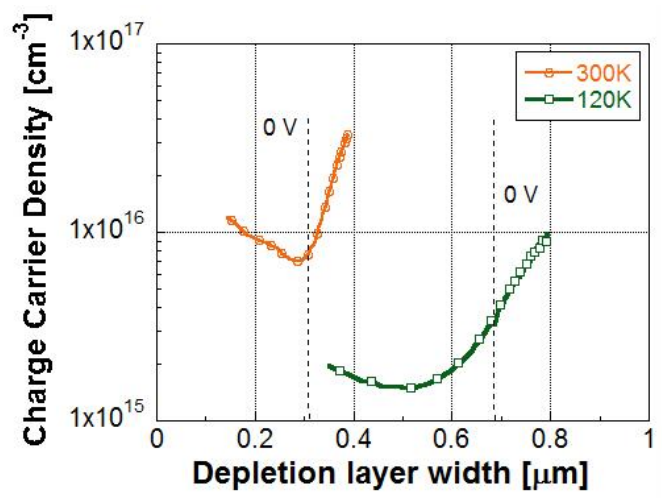

Figure 5. Capacitance-voltage profiles obtained at $300 \mathrm{~K}$ and $120 \mathrm{~K}$ on typical CIGS solar cell with intermediate $\mathrm{NaF}$ buffer-layer. The test signal frequency is $1 \mathrm{MHz}$.

The cell ideality factors obtained from the dark I-V curves at room temperature are typically around 1.5-1.6 indicating that the dark current is dominated by SRH recombination in the space charge region [23]. Finally the open circuit voltage as function of temperature for a typical cell is shown in 
Figure 6, together with a linear fit performed in the linear temperature regime of $230-330 \mathrm{~K}$. The T $=0 \mathrm{~K}$ intercept of this fit is close to $1.2 \mathrm{~V}$, indicating an energy barrier for recombination of approximately $1.2 \mathrm{eV}$. As this value is near to the bandgap-energy of the CIGS absorber the obtained result indicates that recombination in the bulk of the absorber is the dominant recombination mechanism [23].

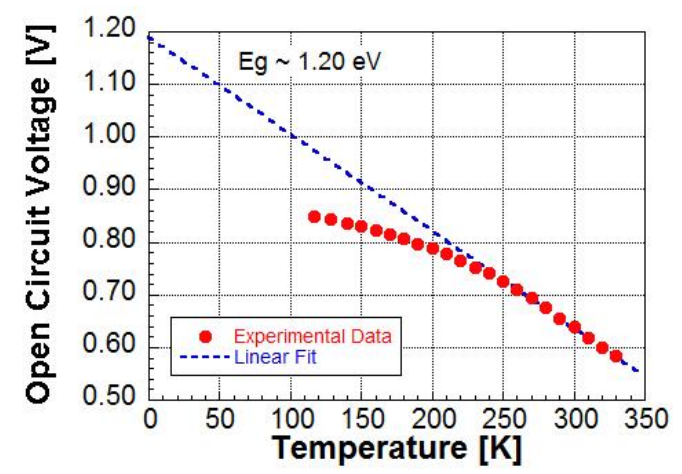

Figure 6. Temperature dependence of Voc of a typical CIGS solar cell fabricated by LTPED. The extrapolated value of $\mathrm{Voc}$ as $\mathrm{T} \rightarrow 0$ corresponds to Eg/q, where Eg is the absorber bandgap and $\mathrm{q}$ is the electron charge.

\subsection{Efficiency and Uniformity of Solar Cells}

The I-V plot and the external quantum efficiency spectrum in Figure 7 refer to a typical test cell with an aperture area of $0.05 \mathrm{~cm}^{2}$ grown at $250{ }^{\circ} \mathrm{C}$.
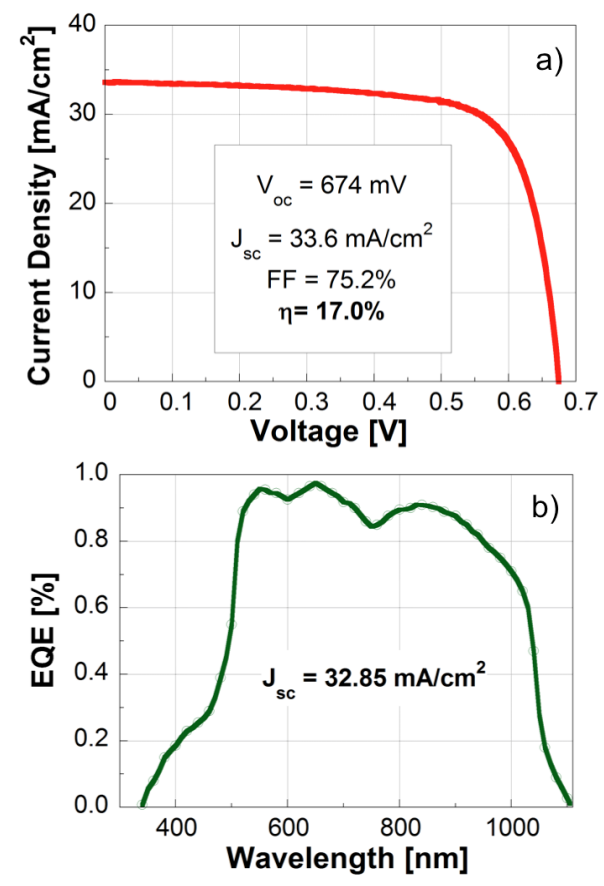

Figure 7. (a) Current-voltage characteristics of a test solar cell under the illumination of a class-A solar simulator; (b) External quantum efficiency spectrum of the same cell.

The light I-V curve was obtained under the illumination of a class-A solar simulator which was also used for the collection of the QE spectrum in combination with a set of 16 narrow-band filters (FB350/1100-10, Thorlabs Inc., Newton, NJ, USA) and a silicon photodiode (Thorlabs FDS-1010-CAL) for the calibration. 
It is important to note that the $17 \%$ efficiency reached by the standard cells is a significant result given that CIGS band-gap grading, K-doping an AR-coating are not included in the device architecture. This is evident in the QE spectrum where both the short and the long wavelength response is clearly reduced with respect to cells where these parameters are properly optimised [8].

The uniformity of solar cell devices over an area of $2.5 \times 2.5 \mathrm{~cm}^{2}$ has been studied by processing 1 square-inch samples into 16 standard cells, with an active area of $0.2 \mathrm{~cm}^{2}$ and mapping the key test cell parameters, Voc, Jsc and FF. The typical standard deviations are $1.5 \%$ for the Voc, $2.1 \%$ for the fill factor, $3.8 \%$ for the Jsc and $4.9 \%$ for the efficiency.

Tests with multiple electron sources (not reported here) confirm the good uniformity of the samples and show that there is no negative interference between neighbouring sources and partially overlapping plasma plumes. This is in agreement with published results on multiple-source pulsed electron deposition of superconducting films [24].

\section{Discussion and Conclusions}

The results illustrated in the previous paragraph show that single stage growth of photovoltaic-quality CIGS by LTPED is possible within a certain window of growth parameters defined in particular by the electron beam energy and the substrate temperature. On the basis of the work done so far it is clear that both the extent of the window and the reproducibility of the samples within the window, critically depend on the stability and reproducibility as well as the time profile of the electron pulses but also on the density and morphology of the targets. Too dense targets require high beam energies to achieve reasonable deposition rates [25] with the risk of fatal damage of the target after a relatively low number of pulses. On the other hand too soft targets may generate a very large quantity of debris even at beam energies very close to the onset of the ablation regime [26].

This conclusion is based on extensive tests done with different combinations of sources and targets whose details will be reported elsewhere.

In view of the industrial scale-up of LTPED a key result reported above is that the interaction between neighbouring sources can be negligible. This ensures that the combined effect of multiple sources is essentially the superposition of the ablation plumes and consequently the uniformity of thickness and composition of a film grown on top of a moving substrate can be accurately predicted and translated into kinematic algorithms for the deposition machine.

The importance of this result is highly enhanced by the very low substrate temperature required by the LTPED process. In fact one of the most obvious applications of the LTPED process at $250{ }^{\circ} \mathrm{C}$ is a roll-to-roll CIGS deposition on thermolabile flexible substrates like plastics or ultra-thin metal foils. Work is in progress to test solutions like this for the manufacturing of highly flexible solar cells for BIPV applications [27].

Several critical issues are still open both on the scientific and the technological fronts. Among the first it is worth mentioning the mechanism of formation of the junction in the presence of a CIGS surface not treated at high temperature and selenium overpressure. The different type of defects and their density may be peculiar of LTPED and may suggest different routes to the optimisation of the junction with respect to CIGS cells grown at high temperature. On the technological front the most important issues are related to the upgrade of the electron beams sources to extend their lifetime and mean time between maintenance. The type and frequency of target reconditioning operations to remove the cumulative damage (morphological and compositional) generated by the beam are also crucial.

\section{Materials and Methods}

The lab-grade LTPED system used in this work (Figure 8) operates in a vacuum chamber pumped down to a base pressure of $\sim 10^{-7}$ mbar. The basic layout includes a horizontal target holder designed to host several circular targets with the diameter of 1 inch and thickness of a few $\mathrm{mm}$. Each target can be positioned under the electron source by rotating the holder around its vertical axis. Two Neocera PEBS-20 pulsed electron sources are mounted at about $45^{\circ}$ with respect to the target holder and are 
operated at a discharge voltage between $12 \mathrm{kV}$ and $18 \mathrm{kV}$ with a triggered pulse repetition rate of $10 \mathrm{~Hz}$. The Mo-coated substrates are fixed upside down on a horizontal sample holder facing the target surface. During the deposition process, Ar gas ( $5 \mathrm{~N}$ purity) is introduced at a pressure of up to $5.0 \times 10^{-3}$ mbar to enable the electron beam generation and stabilise the beam propagation towards the target. The deposition chamber is equipped with a thermographic camera to monitor the average value and the uniformity of the temperature on the growth surface.

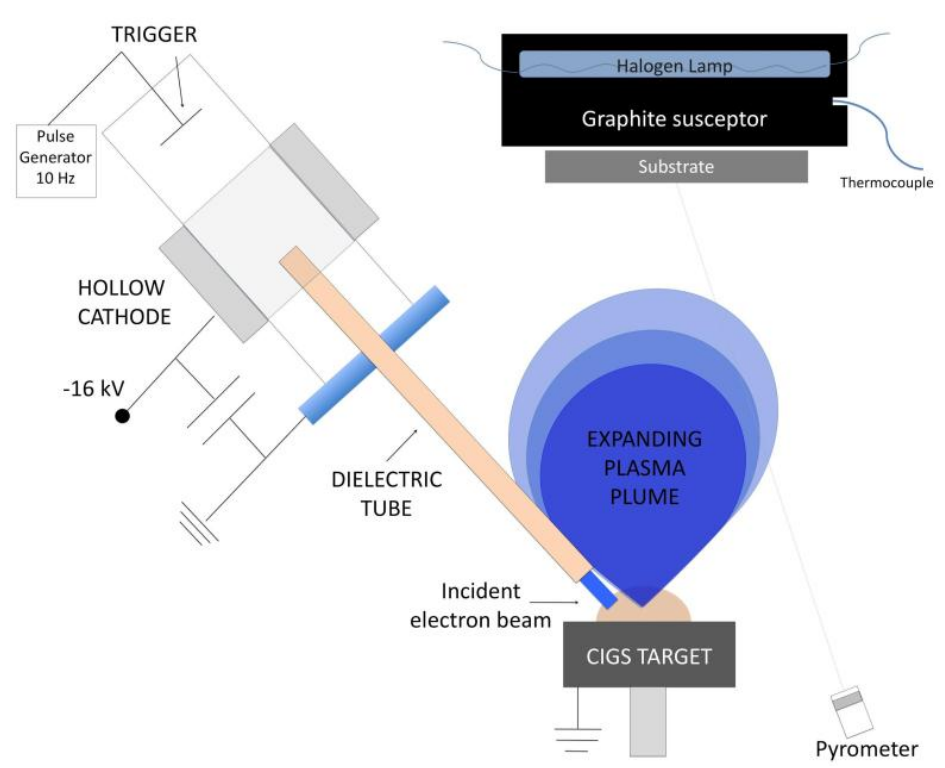

Figure 8. Schematic representation of the Pulsed Electron Deposition technique.

The solar cell devices defined as "standard cells" throughout the paper are grown on soda-lime glass sheets coated with a $\mathrm{Si}_{3} \mathrm{~N}_{4}$ blocking layer and a $0.5 \mu \mathrm{m}$ thick Mo contact. The NaF buffer layer is grown by LTPED at a substrate temperature of $80^{\circ} \mathrm{C}$ to a thickness of the order of $10 \mathrm{~nm}$. After the temperature of the deposition surface is raised to $250{ }^{\circ} \mathrm{C}$ the CIGS absorber is deposited up to a thickness of about $1.6 \mu \mathrm{m}$, monitored by an IR pyrometer [15]. The solar cells are then completed with a $100 \mathrm{~nm}$ thick CdS buffer layer grown by chemical bath deposition followed by $50 \mathrm{~nm}$ of undoped $\mathrm{ZnO}$ and $250 \mathrm{~nm}$ of $\mathrm{Al}: \mathrm{ZnO}$ both grown by RF-sputtering [28].

Acknowledgments: This work was supported by the programmes "Industria 2015" of the Italian Ministry of Economic Development (Grant EE01_00062, "PED4PV") and "Progetto Bandiera-La Fabbrica del Futuro" of the CNR ("MaCISte" project). The authors acknowledge Lucia Nasi, Andrea Zappettini and Mariano Zarcone for useful discussions on the experimental data.

Author Contributions: Stefano Rampino, Matteo Bronzoni and Francesco Bissoli LTPED growth, deposition equipment design and installation, materials characterization; Enos Gombia device modelling and electrical characterization; Francesco Pattini sputtering deposition and sputtering target preparation; Davide Calestani LTPED target preparation; Aldo Kingma and Marco Calicchio device processing and electrical characterization; Nicholas Cavallari device modelling and simulations; Filippo Annoni and Vimalkumar Thottapurath Vijayan chemical bath deposition of buffer layers; Mauro Lomascolo and Arianna Cretì optical characterization; Massimo Mazzer device modelling, electron microscopy, project coordination; Edmondo Gilioli chemical bath deposition of buffer layers, thin film lab coordination.

Conflicts of Interest: The authors declare no conflict of interest.

\section{Abbreviations}

The following abbreviations are used in this manuscript:

CIGS CuInGaSe 2 , i.e. Copper-indium-gallium-diselenide

LTPED Low Temperature Pulsed Electron Deposition 
PV Photovoltaics

BIPV Building Integrated Photovoltaics

SRH Shockley-Read-Hall Recombination

GGI Gallium concentration divided by the sum of gallium and indium concentrations

\section{References}

1. Bazilian, M.; Onyeji, I.; Liebreich, M.; MacGill, I.; Chase, J.; Shah, J.; Gielen, D.; Arent, D.; Landfear, D.; Zhengrong, S. Re-considering the economics of photovoltaic power. Renew. Energy 2013, 53, 329-338. [CrossRef]

2. Green, M.A.; Emery, K.; Hishikawa, Y.; Warta, W.; Dunlop, E.D. Solar cell efficiency tables (Version 45). Prog. Photovolt. Res. Appl. 2015, 23, 1-9. [CrossRef]

3. Friedlmeier, T.M.; Jackson, P.; Bauer, A.; Hariskos, D.; Kiowski, O.; Wuerz, R.; Powalla, M. Improved photocurrent in $\mathrm{Cu}(\mathrm{In}, \mathrm{Ga}) \mathrm{Se} 2$ solar cells: From $20.8 \%$ to $21.7 \%$ efficiency. In Proceedings of the 42nd IEEE Photovoltaic Specialist Conference (PVSC), New Orleans, LA, USA, $14-19$ June 2015; pp. 1-3.

4. Rampino, S.; Bissoli, F.; Gilioli, E.; Pattini, F. Growth of $\mathrm{Cu}(\mathrm{In}, \mathrm{Ga}) \mathrm{Se}_{2}$ thin films by a novel single-stage route based on pulsed electron deposition. Prog. Photovolt. Res. Appl. 2013, 21, 588-594.

5. Rampino, S.; Bronzoni, M.; Colace, L.; Frigeri, P.; Gombia, E.; Maragliano, C.; Mezzadri, F.; Nasi, L.; Seravalli, L.; Pattini, F.; Trevisi, G.; Motapothula, M.; Venkatesan, T.; Gilioli, E. Low-temperature growth of single-crystal $\mathrm{Cu}(\mathrm{In}, \mathrm{Ga}) \mathrm{Se}_{2}$ films by pulsed electron deposition technique. Sol. Energy Mater. Sol. Cells 2015, 133, 82-86. [CrossRef]

6. Liu, J.; Zhuang, D.; Luan, H.; Cao, M.; Xie, M.; Li, X. Preparation of $\mathrm{Cu}(\mathrm{In}, \mathrm{Ga}) \mathrm{Se}_{2}$ thin film by sputtering from $\mathrm{Cu}(\mathrm{In}, \mathrm{Ga}) \mathrm{Se}_{2}$ quaternary target. Prog. Nat. Sci. Mater. Int. 2013, 23, 133-138. [CrossRef]

7. Salomé, P.M.P.; Fjällström, V.; Szaniawski, P.; Leitão, J.P.; Hultqvist, A.; Fernandes, P.A.; Teixeira, J.P.; Falcão, B.P.; Zimmermann, U.; da Cunha, A.F.; et al. A comparison between thin film solar cells made from co-evaporated CuIn1-xGaxSe ${ }_{2}$ using a one-stage process versus a three-stage process. Prog. Photovolt. Res. Appl. 2015, 23, 470-478. [CrossRef]

8. Chirilă, A.; Reinhard, P.; Pianezzi, F.; Bloesch, P.; Uhl, A.R.; Fella, C.; Kranz, L.; Keller, D.; Gretener, C.; Hagendorfer, $\mathrm{H}$.; et al. Potassium-induced surface modification of $\mathrm{Cu}(\mathrm{In}, \mathrm{Ga}) \mathrm{Se}_{2}$ thin films for high-efficiency solar cells. Nat. Mater. 2013, 12, 1107-1111. [CrossRef] [PubMed]

9. Jackson, P.; Hariskos, D.; Wuerz, R.; Kiowski, O.; Bauer, A.; Friedlmeier, T.M.; Powalla, M. Properties of $\mathrm{Cu}(\mathrm{In}, \mathrm{Ga}) \mathrm{Se}_{2}$ solar cells with new record efficiencies up to 21.7\%. Phys. Status Solidi RRL 2015, 9, $28-31$. [CrossRef]

10. Vermang, B.; Fjällström, V.; Gao, X.; Edoff, M. Improved Rear Surface Passivation of Cu(In,Ga)Se Solar Cells: A Combination of an Al O Rear Surface Passivation Layer and Nanosized Local Rear Point Contacts. IEEE J. Photovolt. 2014, 4, 486-492. [CrossRef]

11. Rampino, S.; Armani, N.; Bissoli, F.; Bronzoni, M.; Calestani, D.; Calicchio, M.; Delmonte, N.; Gilioli, E.; Gombia, E.; Mosca, R.; et al. $15 \%$ efficient $\mathrm{Cu}(\mathrm{In}, \mathrm{Ga}) \mathrm{Se}_{2}$ solar cells obtained by low-temperature pulsed electron deposition. Appl. Phy. Lett. 2012, 101, 132107. [CrossRef]

12. Pattini, F.; Bronzoni, M.; Mezzadri, F.; Bissoli, F.; Gilioli, E.; Rampino, S. Dynamics of evaporation from $\mathrm{CuGaSe}_{2}$ targets in pulsed electron deposition technique. J. Phys. D Appl. Phys. 2013, 46, 245101. [CrossRef]

13. Rampino, S.; Pattini, F.; Malagù, C.; Pozzetti, L.; Stefancich, M.; Bronzoni, M. Application of a substrate bias to control the droplet density on $\mathrm{Cu}(\mathrm{In}, \mathrm{Ga}) \mathrm{Se}_{2}$ thin films grown by Pulsed Electron Deposition. Thin Solid Film. 2014, 562, 307-313. [CrossRef]

14. Zappettini, A.; Görög, T.; Zha, M.; Zanotti, L.; Zuccalli, G.; Paorici, C. A new process for synthesizing high-purity stoichiometric cadmium telluride. J. Cryst. Growth 2000, 214, 14-18. [CrossRef]

15. Bronzoni, M.; Stefancich, M.; Rampino, S. Role of substrate temperature on the structural, morphological and optical properties of $\mathrm{CuGaSe}_{2}$ thin films grown by Pulsed Electron Deposition technique. Thin Solid Film. 2012, 520, 7054-7061. [CrossRef]

16. Hsu, C.H.; Su, Y.S.; Wei, S.Y.; Chen, C.H.; Ho, W.H.; Chang, C.; Wu, Y.H.; Lin, C.J.; Lai, C.H. Na-induced efficiency boost for Se-deficient $\mathrm{Cu}(\mathrm{In}, \mathrm{Ga}) \mathrm{Se}_{2}$ solar cells. Prog. Photoolt. Res. Appl. 2015, 23, 1621-1629. [CrossRef] 
17. Shafarman, W.N.; Siebentritt, S.; Stolt, L. Cu(InGa)Se 2 Solar Cells. In Handbook of Photovoltaic Science and Engineering, 2nd ed.; Luque, A., Hegedus, S., Eds.; Wiley: New York, NY, USA, 2011; p. 547.

18. Rudmann, D.; da Cunha, A.F.; Kaelin, M.; Kurdesau, F.; Zogg, H.; Tiwari, A.N.; Bilger, G. Efficiency enhancement of $\mathrm{Cu}(\mathrm{In}, \mathrm{Ga}) \mathrm{Se}_{2}$ solar cells due to post-deposition Na incorporation. Appl. Phy. Lett. 2004, 84, 1129-1131. [CrossRef]

19. Krishnan, R.; Payzant, E.A.; Kacnyzki, R.; Schoop, U.; Britt, J.; Noufi, R.; Anderson, T.J. Reaction kinetics and pathways of $\mathrm{MoSe}_{2}$. In Proceedings of the 35th IEEE Photovoltaic Specialists Conference (PVSC), Honolulu, HI, USA, 20-25 June 2010; pp. 001006-001008.

20. Assmann, L.; Bernède, J.C.; Drici, A.; Amory, C.; Halgand, E.; Morsli, M. Study of the Mo thin films and Mo/CIGS interface properties. Appl. Surf. Sci. 2005, 246, 159-166. [CrossRef]

21. Matson, R.J.; Jamjoum, O.; Buonaquisti, A.D.; Russell, P.E.; Kazmerski, L.L.; Sheldon, P.; Ahrenkiel, R.K. Metal contacts to CuInSe 2 . Sol. Cells 1984, 11, 301-305. [CrossRef]

22. Cwil, M.; Igalson, M.; Zabierowski, P.; Siebentritt, S. Charge and doping distributions by capacitance profiling in $\mathrm{Cu}(\mathrm{In}, \mathrm{Ga}) \mathrm{Se}_{2}$ solar cells. J. Appl. Phy. 2008, 103. [CrossRef]

23. Hegedus, S.S.; Shafarman, W.N. Thin-film solar cells: device measurements and analysis. Prog. Photovolt. Res. Appl. 2004, 12, 155-176. [CrossRef]

24. Harshavardhan, K.S.; Strikovski, M. Pulsed Electron-Beam Deposition of High Temperature Superconducting Films for Coated Conductor Applications. In Second-Generation HTS Conductors; Goyal, A., Ed.; Springer US: New York, NY, USA, 2005; pp. 109-133.

25. Foltyn, S.R.; Muenchausen, R.E.; Estler, R.C.; Peterson, E.; Hutchinson, W.B.; Ott, K.C.; Nogar, N.S.; Hubbard, K.M.; Dye, R.C.; Wu, X.D. Influence of Beam and Target Properties on the Excimer Laser Deposition of Yba2Cu3O7-x Thin Films. In Proceedings of the N-Laser Ablation for Materials Synthesis Symposium, San Francisco, CA, USA, 19-20 April 1990; p. 205.

26. Kim, J.H.; Lee, S.; Im, H.S. The effect of target density and its morphology on $\mathrm{TiO}_{2}$ thin films grown on $\mathrm{Si}$ (100) by PLD. Appl. Surf. Sci. 1999, 151, 6-16. [CrossRef]

27. Rampino, S.; Annoni, F.; Bronzoni, M.; Calicchio, M.; Gombia, E.; Mazzer, M.; Pattini, F.; Gilioli, E. Joule heating-assisted growth of $\mathrm{Cu}(\mathrm{In}, \mathrm{Ga}) \mathrm{Se}_{2}$ solar cells. J. Renew. and Sustain. Energy 2015, 7, 013112. [CrossRef]

28. Pattini, F.; Annoni, F.; Bissoli, F.; Bronzoni, M.; Garcia, J.P.; Gilioli, E.; Rampino, S. Comparative study about Al-doped zinc oxide thin films deposited by Pulsed Electron Deposition and Radio Frequency Magnetron Sputtering as Transparent Conductive Oxide for $\mathrm{Cu}(\mathrm{In}, \mathrm{Ga}) \mathrm{Se}_{2}$-based solar cells. Thin Solid Film. 2015, 582, 317-322. [CrossRef]

(C) 2016 by the authors; licensee MDPI, Basel, Switzerland. This article is an open access article distributed under the terms and conditions of the Creative Commons by Attribution (CC-BY) license (http://creativecommons.org/licenses/by/4.0/). 